\title{
O PLANEJAMENTO TELECOLABORATIVO DE PROFESSORES DE LÍNGUA INGLESA POR MEIO DE DISPOSITIVOS TECNOLÓGICOS
}

\author{
Alex Alves Egido ${ }^{1}$ \\ ORCID: 0000-0001-8014-8651 \\ Givliana Castro Brossi ${ }^{2}$ \\ ORCID: 0000-0003-0130-843X
}

Resumo: Inserida na área da Linguística Aplicada e nos campos de atuação profissional e de formação continuada de professores de língua inglesa, esta investigação centra-se no processo de planejamento telecolaborativo, com suporte de dispositivos tecnológicos síncronos e assíncronos, levado a efeito por três professores formadores. Ao analisar, indutivamente, dados gerados por meio de um questionário, buscou-se respostas para as seguintes perguntas de pesquisa: (i) Que dispositivos tecnológicos foram usados durante o processo de planejamento? (ii) Quais as razões para seus usos? (iii) Que (des)vantagens identificamos? Como resultados, evidenciou-se o uso de diferentes dispositivos tecnológicos de interação

1 Licenciado em Letras - Inglês pela Universidade Estadual de Londrina (UEL). Mestre e doutorando em Estudos da Linguagem pela referida instituição. Atualmente, é professor colaborador no Departamento de Letras Estrangeiras Modernas da UEL e membro da Associação Americana de Pesquisa Educacional (AERA). Seus interesses de pesquisa centram-se em ética na Linguística Aplicada, estudos críticos, metodologia de pesquisa qualitativa e estudos discursivos de orientação foucaultiana. E-mail: (egido.alex.alves@gmail.com).

2 Licenciada em Letras Português/Inglês pela Universidade Estadual de Goiás (UEG). Mestre em Linguística Aplicada pela Universidade de Brasília (UnB) e doutoranda em Estudos da Linguagem pela Universidade Estadual de Londrina (UEL). Atualmente, é docente efetiva no Departamento de Letras da UEG Câmpus Inhumas. Seus interesses de pesquisa centram-se na formação de professores de língua inglesa segundo a perspectiva crítica, ensino de inglês para crianças na escola pública, comunidades de prática de professores de inglês para crianças e ações extensionistas e a transformação social.E-mail: (giulianabrossi7o@gmail.com). 
síncrona e assíncrona, impulsionado pelas diferentes agendas profissionais dos professores formadores, bem como a necessidade de celeridade, gratuidade e as localidades em que os professores se encontravam. Embora poucas desvantagens tenham sido mencionadas, estas centram-se em aspectos externos, enfatizando-se, assim, as vantagens, sendo a principal delas a concretização do planejamento telecolaborativo.

Palavras-chave: Extensão. Ensino de inglês para crianças. Tecnologias emergentes. Planejamento.

\title{
ENGLISH TEACHERS TELECOLLABORATIVE PLANNING THROUGH TECNOLOGICAL DEVICES
}

\begin{abstract}
Established in the area of Applied Linguistics and in the fields of professional performance and English teachers education, this study focuses in the telecollaborative planning process, supported by synchronous and asynchronous technological devices, accomplished by three teachers' educators. Inductively analyzing the generated data through a questionnaire, we sought for answers to the following research questions: (i) What technological devices were used during the planning process? (ii) What were the reasons for their use? (iii) What were the recognized (dis)advantages? As results, we identified the use of different synchronous and asynchronous technological advices for interaction, promoted by diverse professional teachers' educators agendas, as well as the need for speed, gratuity and the locus where the professors were. Although very few disadvantages were mentioned, they are centered in external aspects, emphasizing, therefore, the advantages, such as the embodiment of the telecollaborative planning.
\end{abstract}

Keywords: Extension. Teaching English for children. Emerging technologies. Planning.

\section{EL PLANTEAMIENTO TELE COLABORATIVO DE PROFESORES DE LENGUA INGLESA POR MEDIO DE DISPOSITIVOS TECNOLÓGICOS}

Resumen: Inserida en el área de la lingüística aplicada y en los campos de de la actuación profesional y de formación continua de profesores de lengua inglesa, esta investigación se centra en el proceso de planteamiento tele colaborativo, con soporte de dispositivos tecnológicos, sincronizados y asíncronos, por tres profesores formadores. Al analizar, de manera inductiva, datos generados por medio de cuestionario, se buscó respuestas a las siguientes preguntas: (i) ¿Qué dispositivos tecnológicos fueron usados durante el proceso de planteamiento? (ii) ¿Cuáles razones para sus usos? (iii) ¿Qué (des)ventajas identificamos? Como resultados, se evidenció el uso de diferentes dispositivos tecnológicos, de interacción sincronizada y asíncrona, estimulada por las distintas agendas profesionales de los profesores formadores, bien como la necesidad de celeridad, gratuidad y las localidades en que ellos se encontraban. Aunque pocas desventajas tengan sido mencionadas, ellas se centran en aspectos externos a los profesores enfatizando, así, las ventajas, cuya principal es la concretización del planteamiento tele colaborativo.

Palabras claves: extensión; enseñanza de inglés para niños; tecnologías emergentes; planteamiento. 


\section{CONSIDERAÇÕES INICIAIS}

As tecnologias emergentes ${ }^{3}$ têm possibilitado o desenvolvimento de formas de interação, conectando atores sociais através de espaços fisicamente inexistentes. Isso acontece por meio de dispositivos e plataformas, criando ambientes virtuais propícios ao diálogo, além de relações mediadas por diversos artefatos. Destacamos entre tais dispositivos os drives, as redes sociais e os aplicativos móveis de mensagens instantâneas como, por exemplo, o Whatsapp. Tais dispositivos permitem aos usuários criar, visualizar, distribuir, modificar, armazenar, recuperar, transmitir e receber informações em formato eletrônico, assim como armazenar conteúdos em ambientes virtuais de forma compartilhada. Em outras palavras, as chamadas Tecnologias da Informação e Comunicação (TIC) são possibilidades de novos meios de interação em constante diálogo com o ensino/aprendizagem de línguas estrangeiras (LE).

As tecnologias emergentes (FURTOSO; FERREIRA, 2016) são comumente apresentadas como possíveis solucionadoras de questões relacionadas ao acesso ao ensino/aprendizagem de diferentes formas. No presente artigo, buscamos autorrefletir sobre nossa experiência ao construir um Planejamento Telecolaborativo (PTC) com viés crítico de LE para crianças. Nesse sentido, nosso enfoque recai no que chamamos de PTC para descrever o processo $0^{4}$ de elaboração de um plano de aula que ocorreu, alternadamente, em momentos virtuais e presenciais, sendo majoritariamente naquele formato. Dessa forma, também emprestamos de Furtoso e Ferreira (2016) o termo telecolaboração, utilizado pelos autores para remeter ao ambiente de aprendizagem de LE por meio de parcerias entre falantes de diferentes idiomas, distantes geograficamente, que utilizam redes de computadores para possibilitar o diálogo, o debate e a troca intercultural (BELZ, 2003).

Com base em nossa experiência, afirmamos que as tecnologias emergentes que empregamos serviram como ferramentas mediadoras nas interações e discussões dos professores colaboradores. Por sua vez, estes momentos de

\footnotetext{
Sugerimos a leitura de Furtoso e Ferreira (2016) para maior aprofundamento a respeito do uso do termo tecnologias emergentes. Optamos por esse conceito devido ao ritmo com que mudanças que ocorrem no campo das Tecnologias de Informação e Comunicação.

4 Salientamos que nosso foco é voltado para o processo de elaboração do PTC, e não para o produto final ou seu conteúdo.
} 
telecolaboração viabilizaram a realização de um evento de extensão que atendeu mais de 200 crianças da rede Municipal de Inhumas (Goiás). O PTC tinha como propósito promover uma atividade de sensibilização e uso da língua inglesa, a partir da perspectiva crítica de ensino/aprendizagem de línguas (PENNYCOOK, 2001; 2012). Diante de inúmeras justificativas para a relevância da discussão em torno das tecnologias emergentes, destacamos a dificuldade enfrentada pelos professores colaboradores que atuam em diferentes instituições, tendo em vista a complexidade de adequação da agenda de trabalho de cada um, bem como a distância física entre eles. A par disso, a crescente instabilidade do cenário atual na esfera da educação e a crescente crise orçamentária das universidades contribuíram para causar a redução de recursos e investimento em eventos de extensão.

A nosso ver, o uso de dispositivos tecnológicos que permitem o contato e o diálogo entre parceiros afastados espacialmente, tem-se revelado uma alternativa para a continuidade de ações realizadas envolvendo a comunidade local. Neste artigo, lançamos um olhar para a experiência, que denominamos PTC, isto é, mediado de modo síncrono e assíncrono por intermédio da ferramenta de compartilhamento e armazenamento (Google drive), por vídeoconferências realizadas via aplicativo Skype e em negociações por um grupo de whatsApp.

Apontamos que inicialmente o planejamento para a oficina objetivou ser colaborativo e presencial, realizado em parceria. Entretanto, o uso da tecnologia surgiu como o meio que viabilizou a interação entre os/as parceiros/as, visto que a finalidade não era o uso de tecnologias emergentes, mas a criação e a proposição de uma oficina ancorada nas perspectivas críticas de ensino de LE, que seria ministrada no evento que descreveremos nas seções seguintes.

No intuito de nos adequar às normas desta publicação, optamos por apresentar um recorte com foco nas impressões dos/as professores/as envolvidos no planejamento da ação. Após o aceite para participar do planejamento da oficina e sua posterior execução, iniciamos a negociação de horários com dificuldades, devido ao comprometimento das nossas agendas profissional e acadêmica. Assim, percebemos que a melhor maneira de lidar com tais questões seria propor o documento em Google drive, além de conversas estabelecidas em vídeoconferência e em grupo de whatsApp, configurando o que denominamos neste artigo de Planejamento Telecolaborativo, (doravante PTC), ou seja, realizado de forma presencial e a distância, envolvendo vários colaboradores. Efetuamos o planejamento no decorrer de quatro meses, com um encontro presencial e 
dois a distância (momentos síncronos de interação), bem como ajustes negociados pelo grupo de whatsApp (momentos assíncronos de interação).

Este artigo tem como objetivos refletir acerca de possíveis contribuições do PTC mediado por ferramentas tecnológicas para a formação de professores, além de apresentar nossas impressões, enquanto professores/as-participantes, acerca da experiência de PTC.

\section{LANÇANDO UM OLHAR PARA O PLANEJAMENTO}

O planejamento, segundo Vasconcellos (2000, p. 98) "se coloca no plano da ação, do fazer", partindo de concepções prévias quanto aos entendimentos sobre educação, currículo e conhecimento, ao mesmo tempo em que olha para o contexto em que se pretende estabelecer a práxis que visa à transformação do real. No contexto em questão, o planejamento difere daquele realizado na escola, uma vez que idealizamos o planejamento de uma oficina única, de duração média de 3 horas, de caráter extensionista, e que atende crianças de 10 a 12 anos das escolas públicas municipais de Inhumas.

No entanto, pautamo-nos na concepção de currículo adotada em um planejamento de ensino regular. Em outras palavras, valemo-nos da definição de Sacristán (1995, p. 230) que o compreende como "a complexa trama de experiências que o aluno obtém, incluídos os efeitos do currículo oculto", contemplando, além das atividades dos/as professores/as, as condições do ambiente, as relações sociais que emergem do convívio no ambiente da sala de aula, o material disponível, dentre outros.

Consideramos essencial apontar que o planejamento, cuja realização será tratada neste artigo, foi norteado pela perspectiva crítica do ensino de LI, com foco na problematização de questões voltadas para temas considerados naturalizados, mas que causam sofrimento humano, tais como etnia, gênero, classe social (PESSOA; URZÊDA-FREITAS, 2012). Comungamos da percepção de linguistas aplicados de que

a educação deveria estar engajada com a justiça social, o que quer dizer que os/as professores/as devem não só ensinar o conteúdo de uma disciplina específica, mas também encorajar o pensamento crítico dos/as alunos/as para conscientizá-los/las da opressão e aprendam como lutar contra ela. (PESSOA; URZÊDA-FREITAS, 2012, p.753) ${ }^{5}$

\footnotetext{
No original: education should be committed to social justice, which means that teachers must not only teach the contents of a given subject, but also encourage students' critical thinking so that they can be aware of oppression and learn how to fight against it.
} 
O encorajamento do pensamento crítico tem pautado as aulas ministradas no projeto English for Kids (BROSSI; SILVA, 2018), ao qual a ação que apresentamos é vinculada, por acreditarmos no papel social da LI, inclusive para crianças do ensino fundamental I. Pessoa e Borelli (2011) salientam que é por meio da reflexão colaborativa que os professores se deparam com assuntos geradores de debates que podem ocasionar uma problematização. Um contexto é diferente do outro e, portanto, tem que ser pensado diferente.

Para Vasconcellos (2000), o planejamento colaborativo é uma ferramenta muito importante no processo educativo, pois sua função é tornar as aulas mais produtivas e significativas, uma vez que ao refletir colaborativamente, as ideias vão tomando novos rumos, vão se adequando e se modificando. Em nossa percepção, a tarefa de planejar deixa de ser um trabalho individual para se tornar um trabalho em conjunto, o que de acordo com Little (apud Fullan \& Hargreaves, 2000), revela-se como uma forma contundente de colaboração, criando uma responsabilidade compartilhada, um comprometimento e aperfeiçoamento coletivos aumentando, inclusive, a vontade de contribuir através da crítica e do comentário.

Concordamos com Freire (1987) que "não é no silêncio que os homens se fazem, mas na palavra, no trabalho, na ação-reflexão". Portanto, assim agimos ao desenvolver um PTC envolvendo três professores, e não apenas um professor na solidão de seus pensamentos, juntando esforços para planejar uma ação que tem como objetivo transformar a realidade.

\section{O PLANEJAMENTO MEDIADO PELA TECNOLOGIA}

Kraut et al (2002) consideram que o ambiente virtual não é tão favorável à realização de um trabalho quanto o ambiente onde há proximidade, devido às variáveis que influenciam a comunicação interpessoal e a consciência do grupo, em caráter remoto. Entretanto, concordam que cada vez mais a colaboração com outras pessoas tem ocorrido, independente da proximidade espacial ou temporal.

Como consequência do advento das tecnologias digitais contemporâneas, a construção de redes de relacionamento foi potencializada, possibilitando o surgimento de novas condições "espaciais" (PORTO RENÓ; TYMOSHCHUK; SILVA, 2018).Vamos ao encontro do pensamento de tais autores ao afirmarmos que o desenvolvimento de tecnologias digitais tem facilitado "novas formas de ação coletiva, interação social online (síncrono ou assíncrono), compartilhamento de espaços de colaboração e produção, distribuição e agregação de informações em ambientes online" (PORTO RENÓ; TYMOSHCHUK; SILVA, 2018, p. 198). As 
tecnologias emergentes, dessa forma, se tornaram um meio de construção e expansão do conhecimento ao conectar indivíduos com interesses em comum.

Nesse sentido, Furtoso e Ferreira (2016) afirmam que a telecolaboração tem oferecido suporte para pesquisadores em parceria institucional, localizados geograficamente distantes, otimizando a interação em situações de aprendizagem de LE. Para os autores, os projetos telecolaborativos contribuem para que a interação em LE aconteça em espaços denominados "entre-lugares”, em um território sem delimitação geográfica, resultando em uma "aproximação entre as pessoas, culturas e nações" (FURTOSO; FERREIRA, 2016, p. 545). Acreditamos que ao utilizar as tecnologias emergentes para viabilizar o PTC, nossas interações ocorreram naqueles espaços (i.e. entre-lugares) e possibilitaram uma aproximação entre nós, os/as professores/as participantes do PTC.

\section{DESENHO METODOLÓGICO}

Situamos este estudo como de natureza qualitativa, ao entender que "[....] isso implica enfatizar as qualidades das entidades, os processos e os significados que são examinados [...]" (DENZIN; LINCOLN, 2006, p. 23). No que diz respeito ao tipo de pesquisa, a compreendemos enquanto autorreflexiva, ao considerar que permite "[...]aos indivíduos monitorarem, avaliarem e ajustarem seu comportamento durante a realização de suas atividades" (MACHADO; BORUCHOVITCH, 2015, p. 54). Embora esse conceito seja recorrentemente empregado para discutir práticas reflexivas de professores (ALMEIDA et al, 2018; PINTÉUS, 2016), aqui o adotamos, analogamente, para caracterizar nossa investigação, visto que refletimos sobre nossa própria prática de professores quando da construção de um plano colaborativo.

Buscamos responder às seguintes perguntas de pesquisa: (i) Que dispositivos tecnológicos foram usados durante o processo de planejamento? (ii) Quais as razões para seus usos? (iii) Que (des)vantagens identificamos? A fim de respondê-las, geramos os dados por meio de um questionário eletrônico (COHEN; MANION; MORRISON, 2011) elaborado colaborativamente e composto de cinco questões discursivas (Apêndice A). Os cinco questionamentos enfocam, principalmente, usos, razões, vantagens e limitações dos dispositivos tecnológicos para a construção do plano telecolaborativo.

No que diz respeito ao contexto, entendemos ser composto de uma esfera macro e outra micro. Aquela refere-se à organização e promoção do XV Encontro de Formação de Professores de Língua Estrangeira, sobre o qual abordaremos mais 
detalhadamente abaixo. Esta, ao planejamento da oficina de LI para crianças, razão da construção do PTC. O Encontro de Formação de Professores de Línguas Estrangeiras (ENFOPLE) é um evento extensionista anual, realizado na Universidade Estadual de Goiás (UEG), câmpus Inhumas, há 15 anos. Uma das atividades que compõem a sua programação é a oficina em Língua Inglesa, para alunos de $5^{\circ}$ ano (9 a 11 anos) da rede municipal de Inhumas, já na sua $3^{a}$ edição. A atividade é planejada e organizada, de forma colaborativa, pela equipe do projeto extensionista English for Kids e colaboradores de outras instituições de ensino superior (doravante, IES), voluntariamente.

Nas oficinas, contexto micro, as crianças participam de atividades de ensino de LI por um período de três (3) horas na universidade, com o propósito de propiciar a elas um momento de sensibilização ao uso da língua supracitada, ao mesmo tempo em que visa promover uma ressignificação de sentidos, a partir de temas problematizados. Na edição da qual participamos da construção do PTC, a temática foi o respeito às diferenças ${ }^{6}$, por exemplo.

Por ser uma oficina com foco na perspectiva crítica vista como prática problematizadora (PENNYCOOK, 2001, 2012), compreendemos que seu planejamento não deveria ser responsabilidade de apenas um/a professor/a. Nesse sentido, optamos por um planejamento colaborativo que, durante as interações, passou a ser telecolaborativo (FURTOSO; FERREIRA, 2016), envolvendo os/as professores/ as que aceitaram o desafio de contribuir com o projeto, os quais, especificamente nesta terceira edição, são parceiros/as de outras IES.

Nós, autores/as deste relato de pesquisa, somos participantes, também. No que diz respeito ao cuidado ético do anonimato (CONSELHO NACIONAL DE SAÚDE, 2016), nós o dispensamos ao nos sentirmos confortáveis em analisar nossas próprias experiências. Entendemos essa oportunidade como singular para reflexão de nossa ação enquanto professores/as-pesquisadores/as. Essa é a razão pela qual compreendemos essa investigação como uma pesquisa com (CAMERON et al, 1992).

No que concerne ao método de análise, empregamos leituras indutivas (STAINBACK; STAINBACK, 1984; THOMAS, 2016) por entendê-las como frutíferas para a construção de um entendimento sobre a nossa experiência, cuja base recai nos dados gerados e não em teorias pré-existentes. Dito de outro modo, optamos por não empregar categorias apriorísticas em nossos dados, mas identificar nos mesmos fenômenos recorrentes.

A oficina planejada em telecolaboração teve como base atividades interativas, segundo os preceitos da perspectiva crítica de ensino de línguas, inspirada na obra It's Okay to be different, de Todd Parr. 


\section{AUTORREFLEXÃO SOBRE PLANEJAMENTO TELECOLABORATIVO}

Nesta subseção, apresentamos instâncias de nossas autorreflexões sobre o processo do qual participamos, as quais classificamos como tipos, razões e (des) vantagens dos usos dos dispositivos móveis.

\section{(TIPOS DE) DISPOSITIVOS TECNOLÓGICOS ADOTADOS}

Sobre os dispositivos tecnológicos usados, empregamos alguns de interação síncrona e outros de interação assíncrona. Sobre aquele tipo, mencionamos, em resposta à primeira questão do instrumento de geração de dados (i), a vídeoconferência que permitiu a discussão do plano em construção bem como, em alguns momentos, mensagens em áudio e escritas no (ii) grupo do whatsApp. Ressaltamos que também consideramos esse grupo como de interação assíncrona, tendo em vista que interagíamos, na maioria das vezes, em diferentes momentos. Outros dispositivos tecnológicos de interação assíncrona que usamos foram (iii) o word do Google drive e (iv) o grupo do whatsAap, conforme mencionamos. Esclarecemos que não nos restringimos a indicar tais dispositivos, mas também discorremos sobre a finalidade de cada um no processo de elaboração do plano telecolaborativo (Resposta de Giuliana) e sobre o tipo de interação oportunizada (Resposta de Alex).

\section{RAZÕES PARA USO DE DISPOSITIVOS TECNOLÓGICOS}

Por um lado, elencamos quatro razões pelas quais esses dispositivos tecnológicos foram escolhidos, a saber: agenda profissional, celeridade, gratuidade e localidade. Por outro lado, identificamos somente uma justificativa da razão pela qual esses dispositivos foram eleitos e não outros, a qual classificamos como conhecimento prévio. Passamos à apresentação e discussão dos excertos que suportam essas categorias.

Sobre o argumento que interpretamos como agenda profissional, nós, professores/as-pesquisadores/as, caracterizamos ao leitor, ainda que brevemente, a necessidade de ferramentas que facilitem nosso trabalho, em razão do desenvolvimento de diferentes atividades de ensino, pesquisa e extensão, o que pensamos ser indício de uma insuficiência de tempo para cumprir atividades profissionais: 
No entanto, a demanda do momento, caracterizada pelo nosso distanciamento geográfico e ou diferentes agendas que não nos permitiam dialogar no mesmo instante, nos fez adotar esses dispositivos tecnológicos. (Alex)

O compartilhamento do plano por meio do drive tem sido uma maneira bem usual no decorrer do doutorado, para facilitar e mediar a escrita de artigos acadêmico-científicos, também. Tal opção propiciou a escrita de vários artigos em parceria com autores em diferentes locais. (Giuliana)

A indisponibilidade devido à agenda de cada um dos professores que planejaram [....] (Giuliana)

Em razão da forma como nossa agenda profissional é caracterizada, entendemos ser necessário encontrar meios pelos quais algumas atividades possam ser desenvolvidas com maior celeridade, categoria essa que propomos para o seguinte excerto de Giuliana:

O grupo de whatsapp é um recurso mais interativo e mais ágil que o envio de e-mail, por exemplo. (Giuliana)

Outra razão para a adoção desses dispositivos tecnológicos diz respeito à gratuidade do acesso a eles. Embora tenha sido mencionado somente uma vez nos dados, este fator representa, também, condição decisiva, cujo entendimento é compartilhado por nós, outros dois professores participantes:

Principalmente pela gratuidade destes dispositivos, não seriam uma opção (ao menos ao meu ver) se fossem pagos; e em segundo lugar por possibilitar o diálogo instantâneo, bem como as edições no arquivo do plano. (Duda)

Embora tenhamos identificado elementos relacionados a agenda profissional, como a demanda e a necessidade de celeridade, a razão mencionada com maior frequência foi a localização em que estávamos. Quando desenvolvemos essa análise, nos surpreendemos com esse resultado, porque acreditamos que as pessoas não necessitam estar geograficamente distantes para usarem dispositivos tecnológicos, embora esse tenha sido o motivo com maior recorrência:

No entanto, a demanda do momento, caracterizada pelo nosso distanciamento geográfico e ou diferentes agendas que não nos permitiam dialogar no mesmo instante, nos fez adotar esses dispositivos tecnológicos. (Alex) 
Em outro momento, a vídeo conferência possibilitou a interação entre a Duda e eu, que estávamos no mesmo local, e o Alex que estava em outro local. (Giuliana)

O fato de não conseguirmos estar no mesmo local físico nos dias sugeridos para o planejamento, nos levou a optar por esses dispositivos para a discussão das ideias. (Giuliana)

[...] distância espacial limit[ou] as interações para o planejamento, que só foi possível em decorrência do uso dos dispositivos. (Giuliana)

Quando interpretamos porque empregamos esses dispositivos tecnológicos em detrimento de outros, identificamos somente uma justificativa que classificamos como conhecimento prévio:

Certamente, há vários outros que poderiam ser empregadas. Contudo, voltando à questão de por que esses e não outros, penso que esses porque já sabíamos lidar com eles. Não acho que tínhamos tempo, naquele momento, de parar as interações, aprender sobre novos dispositivos tecnológicos e depois retomar nossos diálogos sobre o planejamento. (Alex)

\section{(DES) VANTAGENS DO USO DESSES DISPOSITIVOS TECNOLÓGICOS}

Nesta terceira e última subseção, voltamos nossos olhares para as vantagens decorrentes do uso dos dispositivos tecnológicos. Antes de fazê-lo, sinalizamos a única ocorrência de desvantagem que identificamos nos dados e que ilustramos abaixo. Nesta ocorrência, Giuliana evidencia questões tanto cognitivas (e.g. falta de atenção e de foco) quanto técnicas (e.g. conexão), pois ambas fogem ao controle dos demais professores/as-pesquisadores/as atuantes na construção do PTC:

A única desvantagem que percebo no uso de vídeoconferência é a dificuldade de acompanhar as reflexões dos outros, seja por causa da conexão de internet, que falha às vezes, seja por desatenção ou falta de foco, uma vez que pessoalmente a expressão corporal, turnos de fala e discussões são mais interativas. (Giuliana)

No último elemento que observamos, ou seja, as vantagens, identificamos duas subcategorias: participação e vozes dos atores sociais e efetivação da proposta. Naquela, inserimos passagens em que enfatizamos o estabelecimento de diálogos, promoção de reflexões e de conscientização, cujos excertos dispomos em seguida: 
[...] a tomada de decisões e negociação de sentidos e das propostas com reflexões acerca do contexto, do tempo disponível, das configurações das atividades (na vídeoconferência). Outra vantagem que percebo é na prática do 'ouvir' o outro uma vez que normalmente, em planejamentos colaborativos presenciais as interações podem ocorrer de maneira menos organizada pois a concentração e o foco estão nas pessoas fisicamente falando. (Giuliana)

[...] os dispositivos tecnológicos permitiram interações e reflexões [pelos professores-pesquisadores] (Alex)

Em relação às vantagens, elas são várias, dentre as quais, cito: promoção do diálogo e tomada de decisão consciente. (Alex)

Não vejo limitações em decorrência do uso. As limitações aconteceram, talvez, por não podermos estar ao mesmo tempo conectados, mas como me referi anteriormente, acredito que estes dispositivos me deram a segurança necessária para não sentir que estava impondo uma mudança, ou sentir que algo estava sendo imposto a mim. (Duda)

Ao usar esses dispositivos tecnológicos, nossa proposta inicial não era somente estabelecer diálogos, promover reflexões e conscientização, mas efetivar a proposta do plano. Em outras palavras, entendemos a promoção do diálogo e a efetivação do plano como duas consequências correlatas da adoção dos dispositivos tecnológicos:

Acredito que o planejamento colaborativo com apoio dos dispositivos que usamos possibilitou o planejamento e compartilhamento do mesmo, e culminou na realização da oficina que foi um sucesso, onde o planejamento mostrou-se adequado à realidade local. (Giuliana)

Não vejo grandes desvantagens no uso dos dispositivos, acredito que, ao contrário, eles beneficiaram a execução da tarefa de forma mais colaborativa. Eu sentia segurança em falar e fazer alterações, pois sabia que os companheiros do plano poderiam ver, aceitar e rejeitar as alterações. (Duda)

\section{CONSIDERAÇÕES FINAIS}

Ao promover o diálogo e possibilitar a tomada de decisões em parceria, nos 'entre-lugares' (FURTOSO; FERREIRA, 2016) do PTC, a utilização dos dispositivos tecnológicos descritos neste relato já atingiu as expectativas e os objetivos inicialmente almejados. Os dispositivos tecnológicos (e.g. Google drive, skype e whatsapp) têm-se mostrado ferramentas relevantes para o processo de ensino/ aprendizagem. No nosso caso, em específico, na preparação do ensino. Neste 
relato de autorreflexão (ALMEIDA et al, 2018; PINTÉUS, 2016), apresentamos argumentos para a presença daqueles no processo de PTC de aulas, ao dar abertura para o desenvolvimento de parcerias síncronas e assíncronas que podem promover resultados promissores e produtivos no campo do planejamento didático.

Tradicionalmente, o planejamento é uma ação solitária do/a professor/a, e que exige criatividade, conhecimento das necessidades dos/as alunos/as, prática de ensino em diferentes metodologias, dentre outros saberes característicos do professor de LI para crianças, especificamente neste caso. Entretanto, consideramos essencial destacar aspectos que o PTC demanda dos/as professores/as que se propuseram realizá-lo, e que elencamos neste estudo: flexibilidade para se adaptar ao contexto, familiaridade com os dispositivos tecnológicos utilizados, ética, empatia, interesse em envolver-se no projeto proposto, e por fim, um bom nível de confiança no comprometimento do/a outro/a.

Ao retomarmos nossas perguntas de pesquisa, identificamos o uso de videoconferências, grupo de whatsApp para troca de mensagens escritas e em áudio, bem como de documentos, e Google Drive que possibilitou a construção e a edição colaborativa do PTC (em resposta à pergunta (i) Que dispositivos tecnológicos foram usados durante o processo de planejamento?). No entanto, compreendemos que nossas escolhas por esses dispositivos, em detrimento de outros, não são neutras, mas respondem às nossas seguintes demandas: diferentes agendas profissionais, necessidade de celeridade, gratuidade dos dispositivos tecnológicos e a localidade geográfica na qual nos encontrávamos (em resposta à segunda pergunta (ii) Quais as razões para seus usos?). Ao autorrefletirmos sobre esse processo de construção do PTC identificamos, como principal vantagem, a efetivação da proposta, ao passo que as desvantagens nos são externas (e.g. conexão insuficiente) (em resposta à terceira pergunta (iii) Que (des)vantagens identificamos?)

Considerando a necessidade de interação entre os colaboradores, a praticidade da utilização dos dispositivos tecnológicos relatados e nossas demandas das agendas profissional e acadêmica, entendemos que a telecolaboração (FURTOSO; FERREIRA, 2016) aproxima os/as pesquisadores/as e professores/as, ao mesmo tempo em que otimiza as interações entre parceiros/as institucionais, possibilitando, mesmo que indiretamente, o desenvolvimento da ação extensionista proposta no evento ENFOPLE. Os dispositivos tecnológicos que retratamos aqui não foram utilizados no decorrer da oficina de inglês para crianças, porém foi por intermédio deles que a oficina se concretizou e atingiu o objetivo de discutir, em uma perspectiva de problematização crítica, o tema das diferenças, foco da atividade ministrada na UEG - Câmpus Inhumas. No entanto, esse é um tema para ser abordado em uma próxima oportunidade. 


\section{REFERÊNCIAS}

ALMEIDA, B. L.; et al. Reflexões sobre a importância da autorreflexão na formação da(o) discente e da(o) docente. In: COLÓQUIO INTERNACIONAL EDUCAÇÃO, CIDADANIA E EXCLUSÃO, V, 2018, Niterói. Anais... Niterói, p. 1-4.

BROSSI, G. C.; SILVA, M. P. English for kids: ensino e pesquisa na extensão. In: FREITAS, C. C. et al. (Org.) Diálogos entre a universidade e a escola na (trans)formação de professores de língua. Anápolis : Ed. UEG, 2018. p. 227-248.

CAMERON, D. et al. Researching language: Issues of Power and Method. New York, NY: Routledge, 1992.

COHEN, L.; MANION, L.; MORRISON, K. Research methods in education. New York, NY: Routledge, 2011.

CONSELHO NACIONAL DE SAÚDE. Resolução CONEP nº 510/2016, de 07 de abril de 2016. Dispõe sobre normas em pesquisa envolvendo seres humanos. Diário Oficial da República Federativa do Brasil, Brasília, 07 abr 2016.

DENZIN, N. K.; LINCOLN, Y. (Org.). O planejamento da pesquisa qualitativa. Thousand Oaks, CA: Sage, 2006.

FULLAN, M.; HARGREAVES, A. A escola como organização aprendente: buscando uma educação de qualidade. Porto Alegre : Artes Médicas, 2000.

FURTOSO, V. A. B.; FERREIRA, M. Nem cá, nem lá, nem acolá: o português falado em espaços de aprendizagem desterritorializantes. In: ALVAREZ, M. L. O.; GONÇALVES, L. (Org.). O Mundo do português e o português no mundo afora: especificidades, implicações e ações. Campinas, SP: Pontes Editores, 2016. p. 525-561. 
KRAUT, R. E., et al. Understanding effects of proximity on collaboration: Implications for technologies to support remote collaborative work. In: HINDS, P.; KIESLER, S. (Org.). Distributed work, Cambridge, MA, US: MIT Press. 2002, p. 137-162.

MACHADO, A. C. T. A.; BORUCHOVITCH, E. As práticas autorreflexivas em cursos de formação inicial e continuada para professores. Psicologia: Ensino \& Formação, São Paulo, v. 6, n. 2, 2015, p. 54-67.

PENNYCOOK, A. Critical applied linguistics: a critical introduction. New Jersey: Lawrence Erlbaum Associates, Inc. 2001.

PENNYCOOK, A. Language and mobility. Unexpected places. Bristol: Multilingual Matters, 2012.

PESSOA, R. R.; BORELLI, J. D. V. P. (Org.). Reflexão e crítica na formação de professores de língua estrangeira. 1. ed. Goiânia: Editora UFG, 2011.

PESSOA, Rosane Rocha.; URZÊDA-FREITAS, Marco Túlio de. Challenges in critical language teaching. TESOL Quarterly, v. 46, p. 753-776, 2012.

PINTÉUS, C. I. D. F. A prática docente: um olhar autorreflexivo. 2016. Dissertação (Mestrado em Ensino de Filosofia no Ensino Secundário) - Universidade do Minho, Porto, 2016.

PORTO RENÓ, Denis; TYMOSHCHUK, Oksana; SILVA, Paula Alexandra. Redes, comunidades e cultura digital: a inovação pela desconexão. Revista Latinoamericana de Comunicación, n. 137, 2018 p. 189-205.

SACRISTÁN, J. Currículo e diversidade cultural: In: SILVA, T. t.; MOREIRA, A. F. (Orgs.). Territórios contestados: o currículo e os novos mapas políticos e culturais. Petrópolis: Vozes, 1995, p. 82-113.

STAINBACK, S.; STAINBACK, W. Methodological considerations in qualitative research. The Association for Persons with Severe Handicaps, Washington, v. 9, n. 4, 1984, p. 296-303. 
THOMAS, D. R. A general inductive approach for analyzing qualitative evaluation data. American Journal of Evaluation, California, v. 27, n. 2, 2006, p. 237-246.

VASCONCELLOS, C. S. Planejamento: projeto de ensino-aprendizagem e projeto político pedagógico. 9 ed. São Paulo: Libertad, 2000. 